\title{
Does the somatostatin analogue octreotide protect against ERCP induced pancreatitis?
}

\author{
K F Binmoeller, A G Harris, R Dumas, C Grimaldi, J P Delmont
}

\begin{abstract}
This study evaluates the effect of the long acting somatostatin analogue octreotide on biochemical and clinical parameters of endoscopic retrograde cholangiopancreatography (ERCP) induced pancreatitis. Altogether 245 patients were randomised to receive either octreotide or isotonic saline. Octreotide $(100 \mu \mathrm{g})$ was administered intravenously five minutes before ERCP and subcutaneously 45 minutes after ERCP. There were no significant differences in the median serum amylase and lipase activities at baseline, eight, and 24 hours after ERCP. Five patients (2\%) developed clinical pancreatitis - three in the octreotide and two in the placebo groups. Excluding patients who developed pancreatitis, $43(18 \%)$ developed abdominal pain after ERCP - 21 in the octreotide and 23 in the placebo groups. There were no significant differences in the median serum amylase and lipase values between the treatment groups. None of the 52 patients who had therapeutic interventions developed pancreatitis. This study suggests that octreotide may not protect against ERCP induced pancreatitis. (Gut 1992; 33: 1129-1133)
\end{abstract}

Endoscopic retrograde cholangiopancreatography (ERCP) is now well established in the diagnosis and treatment of biliary and pancreatic disorders. Although the procedure is generally considered to be safe, complications related to cannulation, contrast injection, and sphincterotomy may occur, and include cholangitis, haemorrhage, perforation, and pancreatitis. ${ }^{12}$ Pancreatitis is the most common of these complications. Clinically severe pancreatitis is reported to occur in $1-7 \%$ of patients, ${ }^{1-5}$ while an asymptomatic increase in pancreatic enzyme activities may occur in up to $70 \% .^{6}$

Various gastrointestinal hormones such as glucagon and calcitonin have been investigated in studies on the prevention of ERCP induced pancreatitis. ${ }^{7-9}$ Somatostatin and a long acting analogue, octreotide, have received particular attention recently. Both are potent known inhibitors of pancreatic secretion. Several studies in healthy volunteers have shown inhibition of baseline and stimulated exocrine pancreatic secretion. ${ }^{10-12}$ Four animal studies of experimentally induced acute pancreatitis have shown an improvement in the pancreatic enzyme response after the infusion of cyclic somatostatin or octreotide. ${ }^{13-16}$ Three of the four studies showed a concomitant improvement in histology..$^{13} 1516$ In three studies, pancreatitis was induced chemically, ${ }^{1+16}$ and in one by ligature of the pancreatic duct ${ }^{13}-\mathrm{a}$ model that is probably more analogous to ERCP induced pancreatitis. In the latter study, somatostatin and octreotide improved the enzyme response, histology, and survival.

Several clinical studies evaluating the effect of somatostatin or octreotide on ERCP induced pancreatic reactions have been published ${ }^{17-26}$ but their results have been conflicting. We undertook a randomised, controlled study in 245 patients to evaluate the effect of the somatostatin analogue octreotide on biochemical and clinical parameters of ERCP induced pancreatitis.

\section{Methods}

This study was designed as a controlled clinical trial, incorporating a double blind placebo control. Exclusion criteria were as follows: (1) age under 18 or above 85 years; (2) pregnancy; (3) albuminuria greater than $500 \mathrm{mg}$ per 24 hours; (4) acute myocardial infarction in the three months before the study; (5) a history of asthma or allergy to drugs. Informed consent was obtained from all the patients. Patients were randomly allocated to receive either the long acting somatostatin analogue octreotide $(n=121)$ or isotonic saline intravenously as a placebo $(n=$ 124). Octreotide was given five minutes before ERCP as an intravenous bolus injection of $100 \mu \mathrm{g}$ and immediately after ERCP as a subcutaneous injection of $100 \mu \mathrm{g}$.

Before ERCP, all patients received premedication consisting of hyoscin-n-butyl bromide (Buscopan) with pethidine (Meperidine) and/or diazepam (Valium) intravenously titrated to age and tolerance. Antibiotics (cefotetan and metronidazol) were given before and after ERCP in patients with cholangitis. All patients were in hospital and confined to bed for at least 24 hours after ERCP. Fasting was maintained for a minimum of six hours.

ERCP was performed with the Olympus JFIT 10 or TJF 10 endoscopes. Contrast medium (65\% angiografine in normal saline) was injected manually in a controlled, titrated fashion under fluoroscopic control. When indicated, sphincterotomy was performed using a standard Erlangen type sphincterotome. Endoprosthesis placement was performed in the conventional manner using a plastic prosthesis for the bile and pancreatic ducts.

Selective cannulation of the biliary and/or pancreatic duct was attempted in all patients. Ductal cannulation was rated as 'easy' if cannulation could be achieved immediately, and as 'difficult' if it required repeated attempts leading to obvious trauma to the papilla.

Assessment of the following clinical parameters was performed before ERCP, immediately after ERCP, and eight and 24 hours after 
TABLE I Clinical data of treatment groups

\begin{tabular}{lcc}
\hline & Octreotide & Placebo \\
\hline No of patients & 121 & 124 \\
Mean age (years) & 58 & 61 \\
Sex M/F & $65 / 56$ & $63 / 60$ \\
Indication for ERCP: & 54 & 51 \\
Chronic abdominal pain & 12 & 16 \\
Suspected pancreatic carcinoma & 9 & 1 \\
Pancreatitis & 1 & 1 \\
Pancreatic cyst & 16 & 27 \\
RUQ pain with abnormal LFTs & 18 & 10 \\
Cholestasis/jaundice & 16 & 11 \\
Chronic alcoholism & 1 & 2 \\
Other & & \\
\hline
\end{tabular}

$\mathrm{ERCP}=$ endoscopic retrograde cholangiopancreatography; $R U Q=$ right upper quadrant; LFTs=liver function tests.

TABLE II Endoscopic retrograde cholangiopancreatograph $(E R C P)$ results

\begin{tabular}{lcc}
\hline & $\begin{array}{l}\text { Octreotide } \\
\text { group }\end{array}$ & $\begin{array}{l}\text { Placebo } \\
\text { group }\end{array}$ \\
\hline Failed & 8 & 1 \\
ERCP & 68 & 83 \\
ERP only & 25 & 23 \\
ERC only & 20 & 17 \\
Volume of contrast media injected & 44 & 45 \\
$\quad$ (mean (cc)) & 45 & 34 \\
Repeated pancreatic duct injections & 22 & 16 \\
Pancreatic duct overfilling & 1 & 2 \\
Papillary 'pre-cut' & 15 & $24^{\star}$ \\
Sphincterotomy & 10 & 2 \\
Endoprosthesis placement: & 0 & 1 \\
$\quad$ Biliary & 0 & \\
\hline
\end{tabular}

^Two pancreatic sphincterotomies.

ERCP: (1) presence and character of abdominal pain; (2) requirement for analgesics; and (3) body temperature. Serum amylase and lipase activities were determined in serial blood samples taken before (baseline) and eight and 24 hours after ERCP. Hyperamylasaemia and hyperlipasaemia were defined as increases above the upper limits of normal, which were $52 \mathrm{IU} / 1$ and $200 \mathrm{IU} / 1$ respectively, before January 11, 1989 , and $10 \mathrm{IU} / 1$ and $208 \mathrm{IU} / 1$, respectively, after January 11, 1989. ERCP associated pancreatitis was defined by clinical features consistent with acute pancreatitis beginning after ERCP and lasting for at least 24 hours, associated with an increase in serum amylase and/or lipase greater than three times the upper limit of normal. The white blood cell count was determined immediately before and at the end of the study; leukocytosis was defined as a white cell count greater than 10000 cells $/ \mathrm{mm}^{3}$.

re 1: Numbers of patients in the octreotide treated and placebo groups with easy and difficult cannulations.

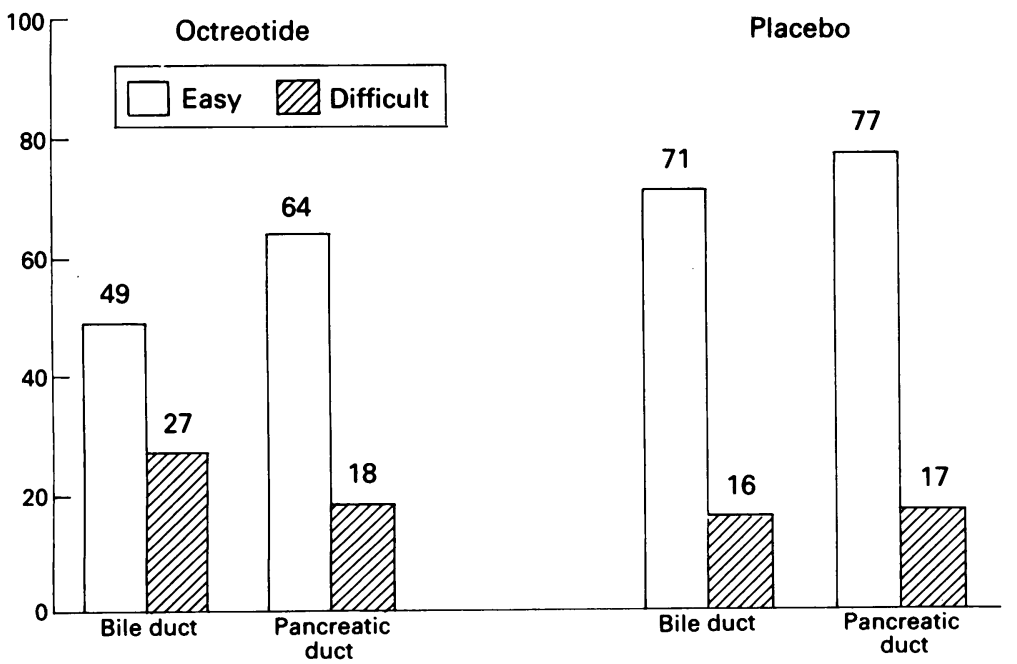

\section{STATISTICAL ANALYSIS}

Comparison of quantitative data between the two groups was performed by Student's $t$ test when normal distribution of the data could be assumed, and by Mann-Whitney $U$ test when distribution could not be assumed to be normal (serum and amylase values). Comparison of categorical data between the two groups was performed with the $\chi^{2}$ test (with Yates's correction when necessary) or with Fischer's exact test. A p value less than 0.05 was the accepted level of significance.

\section{Results}

Comparison of age, sex, and indication for ERCP showed no significant differences between the octreotide and placebo groups (Table I).

ERCP results are shown in Table II. Cannulation of the papilla failed in nine patients. The pancreatic duct was filled in 199 patients (84\%). The octreotide and placebo groups were similar in terms of pancreatic duct filling, number of pancreatic duct injections, volume of contrast media injected, and pancreatic duct overfilling producing acinar opacification. Therapeutic ERCP procedures (39 sphincterotomies and 13 endoprostheses placements) were performed in $18 \%$ of patients.

The numbers of patients in the octreotide and placebo groups with 'easy' and 'difficult' cannulations of the bile and pancreatic ducts is given in Figure 1.

The diagnostic findings at ERCP are detailed in Table III.

Five patients (2\%) developed ERCP associated pancreatitis - three in the octreotide and two in the placebo groups. Table IV details the ERCP and clinical data for these patients. All had undergone injection of the pancreatic duct, three had repeat injections, and two had overfilling resulting in acinar opacification. Two patients had duct pathology seen on pancreatography. None had a therapeutic intervention. The clinical course was uncomplicated in all patients.

Comparison of the median serum amylase and lipase activities at baseline and at eight and 24 hours after ERCP in the octreotide and placebo groups showed no significant differences between the two treatment groups (Fig 2).

Excluding those patients who developed pancreatitis, $43(18 \%)$ developed non-specific post ERCP abdominal pain -21 in the octreotide and

TABLE III Endoscopic retrograde cholangiopancreatographdiagnostic findings

\begin{tabular}{|c|c|c|}
\hline Findings & $\begin{array}{l}\text { Octreotide } \\
\text { group }\end{array}$ & $\begin{array}{l}\text { Placebo } \\
\text { group }\end{array}$ \\
\hline Normal & 62 & 60 \\
\hline \multicolumn{3}{|l|}{ Biliary pathology: } \\
\hline CBD stones & 8 & 13 \\
\hline Malignant stricture & 8 & 6 \\
\hline Papillary stenosis & 0 & 2 \\
\hline Sump syndrome & 0 & 2 \\
\hline Dilated CBD & 11 & 10 \\
\hline Other & 1 & \\
\hline \multicolumn{3}{|l|}{ Pancreatic pathology: } \\
\hline Chronic pancreatitis & 9 & 16 \\
\hline Pancreas divisum & 8 & 6 \\
\hline Dilated pancreatic duct & 3 & 2 \\
\hline Pancreatic carcinoma & 4 & 7 \\
\hline
\end{tabular}

$\mathrm{CBD}=\mathrm{common}$ bile duct 
TABLE IV Clinical characteristics of patients who developed pancreatitis

\begin{tabular}{|c|c|c|c|c|c|c|c|c|}
\hline No & Treatment & Sex & $\begin{array}{l}\text { Age } \\
\text { (yrs) }\end{array}$ & $\begin{array}{l}\text { ERCP } \\
\text { diagnosis }\end{array}$ & $E R P$ & $\begin{array}{l}P D \\
\text { overfilling }\end{array}$ & $\begin{array}{l}\text { Repeated PD } \\
\text { injections }\end{array}$ & $\begin{array}{l}\text { Pain } \\
\text { duration }\end{array}$ \\
\hline 1 & OCT & $\mathrm{F}$ & 58 & Dilated PD & Yes & Yes & Yes & 25 Days \\
\hline 2 & OCT & $M$ & 56 & $\begin{array}{l}\text { Chronic } \\
\text { pancreatitis }\end{array}$ & Yes & $\mathrm{N}$ & No & 24 Hours \\
\hline 3 & OCT & $\mathrm{F}$ & 63 & Normal & Yes & No & No & 24 Hours \\
\hline 4 & PLAC & $\mathrm{F}$ & 61 & Dilated CBD & Yes & No & No & 3 Days \\
\hline 5 & PLAC & M & 55 & Normal & Yes & Yes & Yes & 24 Hours \\
\hline
\end{tabular}

OCT $=$ octreotide $; \mathrm{PLAC}=$ placebo $\mathrm{PD}=$ pancreatic duct $\mathrm{CBD}=$ common bile duct; $\mathrm{ERP}=$ endoscopic retrograde pancreatography.

23 in the placebo group. Comparing the two treatment groups, there were no significant differences in the median serum amylase and lipase activities at baseline and at eight and 24 hours (Fig 2). However, comparing the subgroup of patients that developed abdominal pain with the subgroup that did not, the former had significantly higher median serum amylase and lipase values at both eight and 24 hours (Fig 3 ).

No significant side effects attributable to octreotide were observed during the study.

\section{Discussion}

Our study of 245 patients randomised to receive octreotide or placebo failed to show an effect of octreotide on the biochemical and clinical parameters of ERCP induced pancreatitis. There was no significant difference in median serum amylase or lipase activities, and the occurrence of abdominal pain and clinical pancreatitis was similarly represented in the two treatment groups.

Previous controlled studies evaluating the effect of somatostatin or octreotide on biochemical, clinical, and morphological markers of pancreatitis have shown mixed results. ${ }^{17-26}$ All studies were small in sample size. Comparison is difficult because of variability of drug administration (route, dosage, and schedule), patient composition, and type of ERCP procedures performed.

Two studies by Tulassay et al showed that prophylactic administration of somatostatin or octreotide reduced high pancreatic enzyme activities after ERCP. ${ }^{17}$ In a non-randomised study, 20 patients who received cyclic somatoamylase and lipase activities at baseline and at eight an 24 hours after ERCP in the octreotide treated and placebo groups.

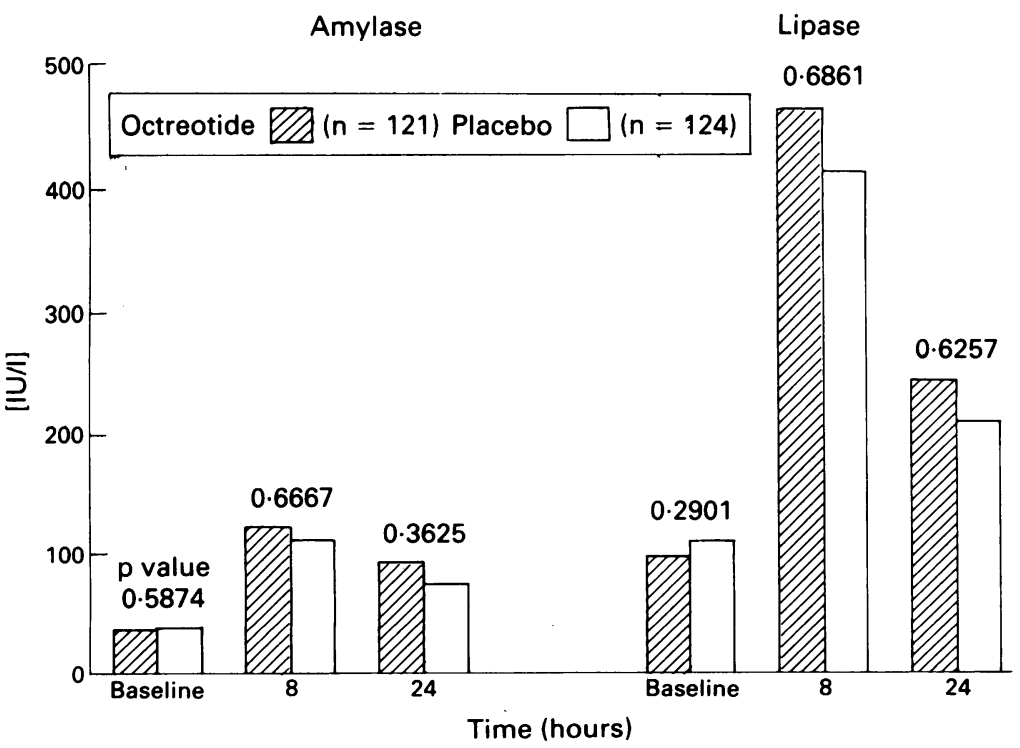

statin had a fourfold reduction in serum amylase values compared with 35 controls. A total of $875 \mu \mathrm{g}$ of somatostatin were administered before and after ERCP over a 150 minute period. ${ }^{17}$ In a randomised double blind study, 29 patients who received octreotide in a dose of $0.1 \mathrm{mg}$ subcutaneously given 45 minutes before ERCP had a significantly smaller increase in pancreatic enzyme activities compared with 34 control subjects. ${ }^{18}$ An analysis of clinical parameters was not performed in either study.

A randomised double blind study of 38 patients by Cicero et al showed a significant reduction in pain intensity and maximum increase in pancreatic enzymes in patients that received $1000 \mu \mathrm{g}$ of cyclic somatostatin before and four hours after ERCP compared with control subjects. ${ }^{19}$ Morphological evaluation of the pancreas with echography in 33 patients showed that those treated with somatostatin had a significantly greater increase in the anteroposterior diameter of the pancreas after injection. In a similarly designed study of 33 patients, Bordas et al showed a significant reduction in abdominal pain and pancreatic enzyme increase in patients who received a bolus injection of natural somatostatin (4 $\mu \mathrm{g} / \mathrm{kg}$ body weight) before ERCP. ${ }^{20}$

In a randomised study of 16 patients with idiopathic recurrent pancreatitis who were undergoing hydrostatic balloon dilation of the pancreatic duct sphincter, somatostatin given intravenously at a dose of $250 \mu \mathrm{g} /$ hour one hour before and 12 hours after dilatation reduced the incidence and severity of acute pancreatitis compared with placebo. ${ }^{21}$ In this study, $43 \%$ of patients developed acute pancreatitis.

In contrast, several controlled studies have failed to show a protective effect of somatostatin or octreotide in ERCP induced pancreatitis. In a study of 56 patients randomised to somatostatin or placebo, somatostatin, administered in a dose of $250 \mu \mathrm{g} /$ hour after contrast media emptying of the pancreatic duct, did not reduce hyperamylasaemia or pancreatitis like pain." A smaller study of 20 patients showed no difference between the median rise in serum amylase values between the somatostatin $(250 \mu \mathrm{g} /$ hour given before ERCP and continued for 24 hours) and placebo groups. ${ }^{23}$ In a study of 54 patients undergoing endoscopic sphincterotomy, the continuous infusion of cyclic somatostatin in a dose of $250 \mu \mathrm{g} /$ hour over 26 hours beginning two hours before ERCP did not significantly reduce pancreatic enzyme rise compared with placebo. ${ }^{-4}$ A study of 26 patients who received somatostatin in a dose of $250 \mu \mathrm{g} /$ hour over 24 hours did not show significant reduction in amylase activities compared with historical controls."

The preliminary results of a multicentre study súggest that octreotide may increase the incidence of ERCP induced pancreatitis. ." $^{-0}$ In a randomised study of 84 patients, octreotide, given in a dose of $100 \mu \mathrm{g}$ intravenously immediately before ERCP and subcutaneously 45 minutes later, significantly increased the incidence of pancreatitis from $11 \%$ (control group) to $35 \%$ (octreotide group).

Controlled clinical studies evaluating somatostatin in acute pancreatitis have not shown 


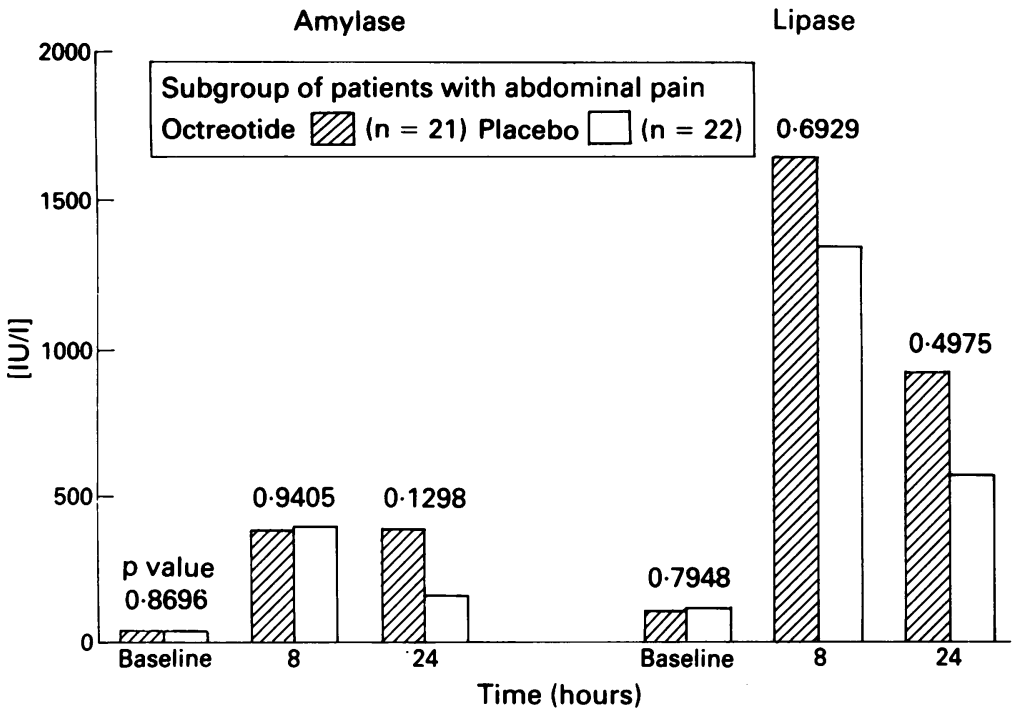

Figure 3: Median serum amylase and lipase activities at baseline and at eight and 24 hours after ERCP in the subgroup of patients with post ERCP abdominal pain. statistically significant advantages in terms of complications and mortality, although trends toward fewer complications ${ }^{27}$ and better pain relief $^{28}$ were observed.

Because of the low incidence of clinical pancreatitis after ERCP, investigators have studied the effect of somatostatin or octreotide on ERCP associated abdominal pain as a surrogate marker of pancreatitis. The incidence of abdominal pain after ERCP, excluding cases of diagnosed pancreatitis, was $18 \%$ in our study. We found that patients who developed abdominal pain had significantly higher median serum amylase and lipase values than asymptomatic patients, a finding that tends to validate abdominal pain as a marker of 'subclinical' pancreatitis. Comparison of the median serum amylase and lipase activities at baseline and eight and 24 hours after ERCP between the octreotide and placebo groups showed no significant differences.

Risk factors for ERCP induced pancreatitis have been identified and include repeated pancreatic duct injections, overfilling of the pancreatic duct, and the presence of a diseased ductal system..$^{25}$ In our study, all patients who developed pancreatitis had injection of the pancreatic duct, three had repeat injections, two had overfilling resulting in acinar opacification, and two had ductal pathology on pancreatography. La Farla et $a l,{ }^{+}$found that endoscopic sphincterotomy significantly increased the incidence of pancreatitis after ERCP, however, none of the patients who underwent sphincterotomy in our study developed pancreatitis.

Eight of nine cases of failed papillary cannulation were in the octreotide group, and patients in the octreotide group tended to have fewer 'easy' as well as more 'difficult' cannulations of the bile and pancreatic ducts (Fig 1). This raises the question of whether octreotide increases sphincter of Oddi pressure, rendering ductal cannulation more difficult. The effect of somatostatin on the human sphincter of Oddi has not been established. We studied the effect of octreotide administered in a dose of $50 \mu \mathrm{g}$ on the sphincter of Oddi using endoscopic manometry in seven patients and found that this hormone increased basal pressure and the frequency of phasic wave contractions appreciably. ${ }^{30}$ In the prairie dog and rabbit, somatostatin has been shown to inhibit sphincter of Oddi motility, ${ }^{31} 32$ but this effect may be species specific. The gastrointestinal hormone cholecystokinine has been shown to have an opposite effect on the human sphincter of Oddi compared with that of the rabbit and prairie dog. ${ }^{32-35}$

Excitatory effects of somatostatin or octreotide on the sphincter of Oddi may impair biliary and pancreatic duct outflow. Such a mechanism is indirectly supported by human studies showing that cholecystokinin, a hormone with antagonistic properties to somatostatin on the sphincter of Oddi, ${ }^{32}{ }^{37}$ increases bile flow into the duodenum. ${ }^{35}$ One study of experimental pancreatography in anaesthesised piglets showed that somatostatin significantly delayed ductal emptying of contrast media compared with control animals. ${ }^{22}$

Based on the above considerations, it is possible that a pancreatic protective effect of octreotide as shown in experimental models of pancreatitis ${ }^{13-16}$ may be clinically offset by an increase of sphincter of Oddi pressure leading to pancreatic duct outflow obstruction. More difficult cannulation at ERCP resulting in papillary oedema may contribute to outflow obstruction. The administration of somatostatin or octreotide after complete emptying of the contrast media filled pancreatic duct may produce different results.

Despite the large number of patients recruited for this study, from a purely statistical standpoint a significantly larger number of subjects would be required to eliminate a type II error in a negative study due to the low incidence of ERCP induced clinical pancreatitis. Such a study would clearly be a major undertaking, and might be difficult to justify in view of mixed results in smaller studies. Studies evaluating somatostatin or octreotide in therapeutic ERCP procedures associated with a higher incidence of pancreatitis, such as manipulation of the pancreatic duct sphincter with hydrostatic balloon dilators, ${ }^{21}$ would be better suited for future studies.

The authors thank Markus Jufer for performing the statistical analyses for this study.

1 Bilbao MK, Dotter CT, Lee TG, Katon RM. Complications of endoscopic retrograde cholangiopancreatography (ERCP) Gastroenterology 1976; 70: 314-20.

2 Geenen JE, Vennes JA, Silvis SE. Resume of a seminar on endoscopic retrograde sphincterotomy (ERS). Gastrointes Endosc 1981; 27: 31-7.

3 Cotton PB. ERCP progress report. Gut 1977; 18: 316-41.

4 Hamilton I, Lintott DHJ, Rothwell J, Axon ATR. Acute pancreatitis following endoscopic retrograde cholangiopancreatography. Clin Radiol 1983; 34: 543-6.

5 LaFerla G, Gordon S, Archibald M, Murray WR. Hyperamylasemia and acute pancreatitis following endoscopic retrograde cholangiopancreatography. Pancreas 1986; 1 : retrograd.

6 Skude G, Wehlin L, Maruyama T, Ariyama J. Hyperamylasemia after duodenoscopy and retrograde cholangiopancreatography. Gut 1976; 17: 127-32.

7 Silvis SE, Vennes JA. The role of glucagon in endoscopic cholangiopancreatography. Gastrointest Endosc 1975; 21 162-3.

8 Odes HS, Bovis BN, Barbezat GO, Bank S. Effect of calcitonin on the serum amylase levels after endoscopic retrograde cholangiopancreatography. Digestion 1977; 16: 180-4.

9 Koch H, Belohlavek D, Schaffner O, Tympner F, Rosch W Demling L. Prospective study for the prevention of pancreatitis following endoscopic retrograde cholangiopancreatography. Endoscopy 1975; 7: 221-4.

10 Creutzfeldt W, Lembcke B, Folsch UR, Schleser S, Koop I. Effect of somatostatin analogue (SMS 201-995, Sandostatin) on pancreatic secretion in humans. Am $\mathcal{F}$ Med 1987; 87 (suppl 5B): 49-54. 
11 Kohler E, Beglinger C, Dettwiler S, Whitehosue I, Gyr K. Effect of a new Somatostatin analogue on pancreatic function in healthy volunteers. Pancreas 1986; $1: 154-9$.

12 Lembcke B, Creutzfeldt W, Schleser S, Ebert R, Shaw C Koop I. Effect of the somatostatin analogue sandostatin (SMS 201-995) on gastrointestinal, pancreatic and biliar function and hormone release in normal men. Digestion 1987; 36: 108-24.

13 Baxter JN, Jenkins SA, Day DW, Roberts NB, Cowell DC, Mackie CR, et al. Effects of somatostatin and a long-acting somatostatin analogue on the prevention and treatment of experimentally induced acute pancreatitis in the rat. BrF Surg 1985; 72: 382-5.

14 Lankisch PG, Koop H, Winckler K, Folsch UR, Creutzfeldt W. Somatostatin therapy of acute experimental pancreatitis. Gut 1977; 18: 713-6.

15 Mann NS, Mauch MJ. Inhibitory effect of cycloheximide, somatostatin and 5-AZA cytidine on acute experimental somatostatin and 5-AZA cytidine on acut
pancreatitis. Am $\mathcal{F}$ Proctol 1981; 32: 24-32.

16 Schwedes U, Althoff PH, Klempa I, Leuschner U, Mothes L, Raptis S, et al. Effect of somatostatin on bile-induced acute haemorrhagic pancreatitis in the dog. Horm Metab Res 1979; 11: $655-61$.

17 Tulassay Z, Papp J, Koranyi L, Szathmari M, Tamas G Jr. Die Wirkung von Somatostatin auf Stoffwechselveranderungen nach ERCP. Wien Klin Wochenschr 1982; 94: 261-5.

18 Tulassay Z, Papp J. The effect of long-acting somatostatin analogue on enzyme changes after endoscopic pancreatography. Gastrointest Endosc 1991; 37: 48-50.

19 Cicero GF, Laugier R, Sahel J, Manganaro M, Sarles H. Effects of somatostatin on clinical, biochemical and morphological changes following ERCP. Ital 7 Gastroenterol 1085; logical change $265-8$.

20 Bordas JM, Toledo V, Mondelo F, Rodes J. Prevention of pancreatic reactions by bolus somatostatin administration in patients undergoing endoscopic retrograde cholangiopancreatography and endoscopic sphincterotomy. Hormone Res 1988; 29: 106-8

21 Guelrud M, Mendoza S, Viera L, Gelrud D. Somatostatin prevents acute pancreatitis after pancreatic duct sphincter hydrostatic balloon dilation in patients with idiopathic recurrent pancreatitis. Gastrointest Endosc 1991; 37: 44-7.

22 Saari A, Kivilaakso E, Schroder T. The influence of somatostatin on pancreatic irritation after pancreatography. An experimental and clinical study. Surg Res Commun 1988; 24: experi

23 Borsch G, Bergbauer M, Nebel W, Sabin G. Effect of somatostatin therapy on amylase level and pancreatitis rate following ERCP. Med Welt 1984; 35: 109-12.
24 Testoni P, Masci E, Bagnolo F, Tittobello A. Endoscopic papillosphincterotomy: prevention of pancreatic reaction by somatostatin. Ital 7 Gastroenterol 1988; 20: 70-3.

25 Tyden G, Nyberg B, Sonnenfeld T, Thulin L. Effect of somatostatin on hyperamylasemia following endoscopic pancreatography. Acta Chir Scand 1986; 530: 43-5.

26 Sternlieb J, Aronchick C, Retig J, Dabeyeis M, Saunder F, Goosenberg R, et al. A multicenter, randomized, controlled trial to evaluate the effect of octreotide on post-ERCP pancreatitis [Abstract]. Am f Gastroenterol 1990; 85: 1260.

27 Choi TK, Mok F, Zhan WH, Fan ST, Lai ECS, Wong J Somatostatin in the treatment of acute pancreatitis: a prospective randomised controlled trial. Gut 1989; 30: 223-7.

28 D'Amigo D, Favia G, Biastiato R, Casaccia M, Falcone F, Fersini $M$, et al. The use of somatostatin in acute pancreatitisresults of a multicenter trial. Hepatogastroenterology 1990; results of

29 Lotveit T, Larsen S, Gronseth K, Osnes M. The probability of pancreatitis after pancreatic parenchymatography with a non-ionic contrast medium. Scand $\mathcal{F}$ Gastroenterol 1987; 22: $111-6$

30 Binmoeller KF, Dumas R, Harris AG, Delmont JP. Effect of somatostatin analog octreotide on human sphincter of Oddi. Dig Dis Sci 1992; 37: 773-7.

31 Ahrendt SA, McGuire GE, Lillemoe KD, Trias M, Kaloo A, Pitt HA. Somatostatin inhibits sphincter of Oddi motility. Gastroenterology 1990; 98: A242.

32 Adami GF, Leandri R, Sarles JC. Action de la somatostatin sur le sphincter d'Oddi du lapin 'in vivo'. Inter-relations somatostatin-cholecystokinine. Gastroenterol Clin Biol 1986; 10: $108-11$.

33 Muller EL, Grace PA, Conter RL, Roslyn JJ, Pitt HA. Influence of motilin and cholecystokinin on sphincter of Oddi and duodenal motility. Am $\mathcal{F}$ Physiol 1987; 253: G679-83

34 Toouli J. Sphincter of Oddi motility. Br F Surg 1984; 71: 251-6.

35 Sarles JC, Devaux MA, Echinard C, Castignini A. Action of cholecystokinin and caerulein on the rabbit sphincter of Oddi. Digestion 1976; 14: 415-23.

36 Ahrendt SA, Kaufman HS, Pitt HA, Lillemoe KD. Octreotide inhibits and CCK stimulates prairie dog sphincter of Oddi motility via noncholinergic pathways. Sphincter of Oddi motility via

37 Ashkin JR, Lyon DT, Shull SD, Wagner CJ, Soloway RD, et al. Factors affecting delivery of bile into the duodenum in man. Gastroenterology 1978; 74: 560-5. 